\title{
O Escola sem Partido no Amazonas: \\ diferentes concepções educacionais
}

\author{
"School without Party" in Amazonas: \\ different education concepts
}

\section{La Escuela sin Partido en el Amazonas: \\ diferentes conceptos educativos}

REINALDO OLIVEIRA MENEZES*

Universidade Federal do Amazonas, Manaus- AM, Brasil.

MARCINEUZA SANTOS DE JESUS ${ }^{* *}$

Universidade Federal do Amazonas, Manaus- AM, Brasil.

FABIANE MAIA GARCIA ${ }^{* * *}$

Universidade Federal do Amazonas, Manaus- AM, Brasil.

HELLEN CRISTINA PICANÇO SIMAS ${ }^{* * * *}$

Universidade Federal do Amazonas, Manaus- AM, Brasil.

MÁRCIO DE OLIVEIRA

Universidade Federal do Amazonas, Manaus- AM, Brasil.

* É assistente Social, mestrando em Educação e graduando em Filosofia, ambas pela Universidade Federal do Amazonas. E-mail: <reinaldo_bamn01@hotmail.com>.

** É graduada em Pedagogia e mestranda em Educação pela Universidade Federal do Amazonas. E-mail: <santosmarcineuza@gmail.com>.

*** É doutora em Educação pela Universidade do Minho e professora da Universidade Federal do Amazonas. E-mail:<fgarcia@ufam.edu.br>.

**** É graduada em Letras pela Universidade Federal do Amazonas, mestre e doutora em Linguística pela Universidade Federal da Paraíba. Atualmente é professora da Universidade Federal do Amazonas e líder do Núcleo de Estudos de Linguagens da Amazônia (NEL-AM/CNPq). E-mail: <india.parintintins@gmail.com>.

**** É doutor em Educação pela Universidade Estadual de Maringá e professor da Universidade Federal do Amazonas. Integra o Núcleo de Estudos e Pesquisas em Diversidade Sexual (NUDISEX). E-mail: $<$ marcio.1808@hotmail.com>. 
RESUMO: O artigo analisa o Programa Escola Sem Partido(EsP), proposto pelo Projeto de Lei Ordinária 102/2016 do estado do Amazonas, cujo objetivo é sua inserção no âmbito da rede estadual de educação. É uma pesquisa de natureza documental e bibliográfica, que se ancora no Projeto de Lei, na Constituição Federal de 1988 e LDBEN (Lei 9.394/1996) e se fundamenta em teóricos tais como Frigotto, para discutir os sentidos e significados do programa EsP, do princípio de neutralidade e do ideal de doutrinação, à luz da própria história da concepção educacional no Brasil.

Palavras-chave: Educação. Programa Escola Sem Partido. Neutralidade. Doutrinação. PLO 102/2016.

\begin{abstract}
ABSRACT: The article analyzes the School without Party Program (EsP), proposed by the state of Amazonas' Ordinary Law Project 102/2016, which has its insertion in the public-school system as its main objective. It is a research of documental and bibliographical nature that is based in the Law Project, in the Federal Constitution of 1988 and LDBEN (Law 9.394/1996), and has its fundament in theorists such as Frigotto; in order to discuss the point and meanings of the EsP program, its neutrality principles, and indoctrination ideals, in the sight of the very History of the education concepts in Brazil.

Keywords: Education. School without Party Program. Neutrality. Indoctrination. PLO 102/2016.
\end{abstract}

RESUMEN: El artículo analiza el Programa Escuela Sin Partido (ESP), propuesto por el Proyecto de Ley Ordinaria 102/2016 del estado de Amazonas, cuyo objetivo es su inserción dentro de la red educativa estatal. Se trata de una investigación de carácter documental y bibliográfico, que está anclado en el Proyecto de Ley, en la Constitución Federal de 1988 y en la LDBEN (Ley 9.394/1996) y se basa en teóricos como Frigotto, para discutir los sentidos y significados del programa ESP, el principio de neutralidad y el ideal de adoctrinamiento, a la luz de la propia historia de la concepción educativa en Brasil.

Palabras clave: Educación. Programa Escuela Sin Partido. Neutralidad. Adoctrinamiento. PLO 102/2016. 


\section{Introdução}

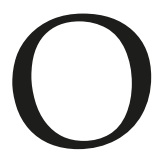

artigo analisa o Programa Escola Sem Partido (EsP) proposto pelo Projeto de

Lei Ordinária 102/2016 do estado do Amazonas, cujo objetivo é sua inserção no âmbito da rede estadual de educação. ${ }^{1}$ É uma pesquisa de natureza documental e bibliográfica, que se ancora neste PL, na Constituição da República Federativa do Brasil de 1988 (BRASIL, 1988) e na Lei de Diretrizes e Bases da Educação Nacional (LDBEN 9.394/1996) (BRASIL, 1996) e se fundamenta em teóricos como Frigotto (2017) para discutir os sentidos e significados do programa EsP, do princípio de neutralidade e do ideal de doutrinação à luz da própria história da concepção educacional no Brasil a qual revela que a educação esteve predominantemente alinhada à ideologia da classe dominante.

Atualmente, a concepção educacional no Brasil é predominantemente econômica e se embasa na ideologia de um segmento da classe dominante, o neoliberalismo, cujas nuances podem ser percebidas na educação pela centralização do financiamento das políticas educacionais por organismos financeiros internacionais, que, como consequência, exercem seu controle ideológico.

OPLO 102/2016 fundamenta-se em um (contra)movimento denominado Escola sem Partido, coordenado por Miguel Nagib, que ganhou ampla repercussão a partir de 2013 e tem sido fortemente discutido nas redes sociais. $\mathrm{O}$ aparato midiático a que se destina o EsP é dividido em dois grandes grupos, principalmente: de um lado, a crítica de pesquisadores e estudiosos, sobretudo da área da educação; do outro, o apoio de grupos conservadores com ideias e práticas reacionárias.

No campo educacional, ganhou destaque um estudioso bastante dedicado às pesquisas relacionadas ao sentido social da educação e o trabalho docente, Frigotto (2017), que demonstra certa preocupação com a repercussão desse PLO e as reações desencadeadas a partir dele, definindo-o como a "esfinge que ameaça a educação e a sociedade brasileira".

Dentre tais reações, o Projeto de Lei (PL) 867 de 2015, apresentado pelo Deputado Izalci do PSDB-DF, cuja proposta é de inclusão, nas Diretrizes e Bases da Educação Nacional, do "Programa Escola Sem Partido" em trâmite na Câmara Federal, cuja influência chegou ao Amazonas na forma de Projeto de Lei Ordinário (PLO). Logo, o PLO 102/2016 é uma extensão do PL 867/2015.

O resultado dessa análise aponta que o PLO 102/2016 é a materialização da própria contradição pois defende uma neutralidade que ela não expressa, porque manifesta em suas proposições uma ideologia, no caso, a burguesa, alinhada ao ideal neoliberal ortodoxo. Quanto à doutrinação, o projeto ignora o fato de que os conteúdos ministrados em sala não são propostos por um único professor, mas por um conjunto de diretrizes curriculares estabelecidas pelo Ministério da Educação. Em síntese, o Programa Escola Sem Partido insere-se em um contexto de desmonte dos bens sociais, preconizado por uma nova crise do capital. 


\section{Concepções de educação no Brasil}

A educação, ao longo da história do Brasil, esteve predominantemente alinhada à ideologia da classe dominante. Do período colonial ao Primeiro Império, ela visou principalmente a um caráter civilizatório, sob rEsPonsabilidade da igreja. Teixeira (1989:61) retrata uma educação dual, com características fundamentadas nas condições socioeconômicas dos indivíduos, às quais esta era destinada:

Os índios, quando não eram escravizados, recebiam uma educação de evangelização nos seus próprios aldeamentos, sob a guarda e proteção dos jesuítas. Os escravos eram educados pelo trabalho forçado e vida nas senzalas. O branco recebia uma educação escolar de qualidade, baseada no saber medieval greco-latino, em sua interpretação teológica ou aristotélica tomista.

Isso porque, nesse momento, a cultura era entendida numa perspectiva "[...] universal, individual, elitista, prescritiva e normativa", difundida pela pedagogia clássica (CANDAU, 2000:18), por isso a visão de mundo e de cultura que predominava no contexto brasileiro era a eurocêntrica. Destarte, os moldes europeus eram a referência, de modo que tudo que fosse diferente, era considerado inferior, logo, precisava ser modificado, ou como o próprio Teixeira (1989) relata, civilizado.

Veiga (2008:504) aponta que "[...] a escola era, então, entendida como forma de civilizar os grupos vistos pelas elites como impeditivos da coesão social brasileira". Por isso, compreendemos que a concepção de educação era a civilizacional, que basicamente significou a negação e o silenciamento da diversidade cultural da população brasileira e a negação da educação como um direito de todos.

Isso ocorre porque, do ponto de vista sociológico, a educação

[...] sempre expressa uma doutrina pedagógica, a qual implícita ou explicitamente se baseia em uma filosofia de vida, concepção de homem e sociedade. Numa realidade concreta, o processo educacional se dá através de instituições EsPecíficas (família, igreja, escola, comunidade) que se tornam porta-vozes de uma determinada doutrina pedagógica (FREITAG, 2005:34).

A doutrina pedagógica e a concepção de ser humano e sociedade que prevalecia na educação nesse período se baseavam, principalmente, no ideal europeu/elitista. Com relação ao ideal europeu, pode ser percebido em dois momentos: o primeiro pela perspectiva civilizacional que a educação oferecida pelos jesuítas possuía, já relatada anteriormente, e, no segundo momento, pelos ideais iluministas, que irradiavam no século XIX para o Brasil. Sobre esse segundo momento, diz Faria Filho (2015:140):

O ideário civilizatório iluminista irradiava-se, a partir da Europa, para boa parte do mundo e, também, para o Brasil. Como componente central desse ideário estava a ideia da necessidade de alargar as possibilidades de acesso de um número cada vez maior de pessoas às instituições e práticas civilizatórias. O teatro, o jornal, o 
No que diz respeito ao elitismo, ele se manifesta pelo fato de os sistemas educacionais brasileiros, organizados ao longo da história, serem construídos para atender aos interesses sociopolíticos das elites. As camadas populares, ampla maioria do povo brasileiro, ficavam excluídas: índios, escravos desafricanizados, mamelucos, cafuzos e brancos pobres (FERREIRA Jr.; BITTAR, 2005:14-15)

Portanto, nesse período, a função da educação era basicamente de reprodução das relações de dominação e a de reprodução da ideologia dominante, uma vez que a escola como mecanismo de realocação dos indivíduos na estrutura de classes era dispensável (FREITAG, 2005).

O elitismo não é revertido ao longo da história do Brasil, no entanto, a educação ganha novas funções e significações e um contexto de disputa em torno dela é instaurado a partir da década de 30 do século XX, reflexo da crise capitalista de 1929, que, no Brasil, materializou-se na crise da superprodução do café.

A economia e a política brasileira foram fortemente abaladas pelos acontecimentos mundiais das três primeiras décadas do século $X X^{2}$, e ainda depois da crise de 19291932, quando se abre uma época de expansão acelerada das relações capitalistas entre nós, com imensas repercussões para as classes sociais, o Estado e as rEsPostas à questão social (BEHRING, 2011).

A partir desse momento, o Brasil passa por uma modernização econômica, que implica o surgimento de novas frações burguesas. Até então a elite cafeeira era o segmento burguês dominante, após a crise, emergem no cenário nacional outras frações como, por exemplo, a elite açucareira, da carne e do setor industrial. Juntamente com isso, ocorrem as insurreições sociais, a chamada questão social brasileira, que se configura na existência de grupos marginalizados da sociedade reivindicando direitos, como o da educação.

Sobre isso, Freitag (2005:91) afirma que, no início do período que caracterizava o modelo econômico da substituição de importações, ocorre uma tomada de consciência por parte da sociedade política, da importância estratégica do sistema educacional para assegurar e consolidar as mudanças estruturais ocorridas tanto na infra como na superestrutura.

A partir desse momento, a Igreja passa a ter cada vez menos influência sobre a educação e o Estado assume as rédeas da política educacional. Esse momento é marcado também pelo enfrentamento das questões sociais. Behring (2011) relata que a forte disputa pela hegemonia e pela direção do processo de modernização acaba por levar à implantação da ditadura de Vargas em 1937, que combateu fortemente os movimentos sociais, com a polícia, ao mesmo tempo em que efetivava algumas medidas de cunho social, como a criação do Ministério da Educação e Saúde e o Conselho Nacional da Educação, na tentativa de conseguir a legitimação do seu governo por parte da sociedade civil, “[...] 
buscando transformar a luta de classes em colaboração de classes" (BEHRING, 2011:106), instalando, assim, o Estado de compromisso.

Nesse sentido, Freitag (2005:92) revela que:

\begin{abstract}
A política educacional do Estado Novo não se limita a simples legislação e sua implantação. Essa política visa, acima de tudo, transformar o sistema educacional em um instrumento mais eficaz de manipulação das classes subalternas. Outrora totalmente excluídas do acesso ao sistema educacional, agora se lhes abre generosamente uma chance. São criadas as escolas técnicas profissionalizantes (para as classes menos favorecidas).
\end{abstract}

Fica evidente que a educação direcionada às classes mais baixas socialmente era tão somente um processo tecnicista, em que o foco era dado na organização do processo, deixando em segundo plano alunos e professores; buscava-se a formação de mão de obra para atender às necessidades do capitalismo. No entanto, não se pode negar que essas medidas, mesmo tendo um caráter direcionado à economia, possibilitaram conquistas significativas no campo social, como a possibilidade de grupos historicamente marginalizados acessarem a educação.

O período que se segue à ditadura de Vargas, que vai de 1946 a 1964, no Brasil, instaura a substituição do modelo agrário-exportador pelo nacional-desenvolvimentista, impulsionado pela II Guerra Mundial. No entanto, Pasinato (2013) evidenciará que, no pós-guerra, ocorrerá a cristalização da supremacia norte-americana e que não tardou muito para ocorrer a invasão cultural e econômica dessa nação no País.

Em relação à educação desse período, a Constituição de 1946 refletiu o processo de redemocratização, após a queda de Getúlio Vargas, defendendo a educação como direito de todos. Em 1948, o ministro da Educação, Clemente Mariano, apresentou o anteprojeto da Lei de Diretrizes e Bases da Educação. Além de escolanovistas, participaram diversos católicos na discussão desse tema. O percurso do projeto foi tumultuado e estendeu-se até 1961, data da sua promulgação (PASINATO, 2013).

Sobre a Lei de Diretrizes e Bases da Educação Nacional de 1961, Freitag (2005) adverte que ela reflete as contradições e os conflitos que caracterizam as próprias frações de classe da burguesia brasileira. Apesar de ainda conter certos elementos populistas, a lei não deixa de ter um caráter elitista. Ao mesmo tempo que dissolve formalmente a dualidade anterior do ensino (cursos propedêuticos para as classes dominantes e profissionalizantes para as classes médias) pela equivalência e flexibilidade dos cursos de nível médio, cria nesse mesmo nível uma barreira quase intransponível, assegurando ao setor privado a continuidade do seu controle.

Após esse período, instala-se no Brasil um clima de crise econômica e instabilidade política marcado pela renúncia de Jânio Quadros em 1961, a conturbada posse de João Goulart e a intensa agitação em prol dos seus projetos de "reformas de base", culminando no golpe civil-militar de 1964, que levou os militares ao poder (SBARDELLOTO, 2013). A educação foi marcada por disputas: 
No campo da educação, os trâmites da autoritária Constituição de 1967 deflagraram um embate de forças entre os Ministérios da Educação e do Planejamento. Nesta correlação de forças, a gratuidade do ensino primário e outros elementos da organização e funcionamento do ensino são assegurados pelo Ministério da Educação, porém este teve que aceitar dois pontos defendidos pelo Ministério do Planejamento, fundamentados na Teoria do Capital Humano. O discurso de Aderbal Jurema, representante da Aliança Renovadora Nacional - ARENA, durante o debate constitucional deixa clara a predominância da concepção de educação como um capital humano, numa relação determinista e descontextualizada entre "educação e desenvolvimento" e amparada no conceito de "educação como investimento" (SBARDELLOTO, 2013:10-11).

A teoria do capital humano, que embasaria a partir daí a lógica educacional no Brasil, é compreendida como "[...] aquela que prega e deposita fortemente o investimento na educação como a forma de provocar uma modificação social" (SILVA; LENARDÃO, 2019: 518). Nessa lógica, tal investimento busca aprimorar as habilidades dos indivíduos, de modo que influenciaria positivamente no crescimento econômico de um determinado local.

Portanto, “[...] a educação, então, é o principal capital humano enquanto é concebida como produtora de capacidade de trabalho, potenciadora do fator trabalho. Neste sentido, é um investimento como qualquer outro" (FRIGOTTO, 2010:51), de tal maneira que investir em educação significa investir em capital.

Nessa perspectiva, a educação é entendida como aquela capaz de diminuir as desigualdades sociais, logo, o Estado, ao invés de investir em recursos físicos, investiria em capital humano. $\mathrm{O}$ conceito de capital humano ou, mais extensivamente, de recursos humanos, busca traduzir o montante de investimento que uma nação faz ou os indivíduos fazem, na expectativa de retornos adicionais futuros. Do ponto de vista macroeconômico, o investimento no "fator humano" passa a significar um dos determinantes básicos para o aumento da produtividade e elemento de superação do atraso econômico. Do ponto de vista microeconômico, constitui-se no fator explicativo das diferenças individuais de produtividade e de renda e, consequentemente, de mobilidade social (FRIGOTTO, 2010:51).

Essa teoria do capital humano explica a disputa pelo controle ideológico da educação, travada entre setores da sociedade civil e instituições econômicas, intensificada a partir da década de 70, com uma nova crise do capital. O diagnóstico da crise no Brasil recai sobre o Estado e, segundo Peroni e Caetano (2012:58), dentre as estratégias para a superação estão o neoliberalismo, a globalização e a reestruturação produtiva, que já estavam em curso no resto do mundo:

No plano ideológico, a teoria neoliberal afirma que o Estado é o culpado pela crise, já que, para atender às demandas em um período democrático, gasta demais, provocando déficit fiscal. Por consequência, as políticas sociais e a democracia devem ser contidas para que os ajustes necessários ao bom andamento do mercado sejam efetuados. Foi o chamado Estado mínimo para as políticas sociais e máximo para o capital, este é rEsPonsabilizado pela crise [...] 
Como o culpado da crise é o Estado, entra em curso a proposta de reformá-lo. Essa reforma culmina na instituição do Estado neoliberal, que se caracteriza por ser mínimo para o social e máximo para o capital e se reflete na educação a partir da centralização das políticas educacionais por parte do Governo Federal. Ele passa a exercer o controle ideológico da educação, por meio dos parâmetros curriculares e da avaliação institucional; por outro lado, ocorre a descentralização de recursos, inclusive desobrigando a União do financiamento da educação básica (PERONI; CAETANO, 2012).

Com a instituição do neoliberalismo, a educação passa a não ser somente rEsPonsável por preparar mão de obra para o mercado e diminuir as desigualdades sociais, mas ela mesma passa a ser mercadoria. Fato evidenciado pela Lei de Diretrizes e Bases da Educação Nacional - LDBEN 1996, a qual assegura no Art. 7º:
O ensino é livre à iniciativa privada, atendidas as seguintes condições:
I - cumprimento das normas gerais da educação nacional e do rEsPectivo sistema de ensino;
II - autorização de funcionamento e avaliação de qualidade pelo Poder Público;
III - capacidade de autofinanciamento, ressalvado o previsto no art. 213 da Consti- tuição Federal (BRASIL, 1996, art. $7^{\circ}$ ).

Sobre esse aspecto, Canan (2016) considera que as carências econômicas de países como o Brasil os tornaram terrenos férteis para a prática da política imperialista de cunho neoliberal, conduzindo a educação a reduzir-se a uma perspectiva mercantilista, que a faz confundir seu valor enquanto possibilidade de construir no sujeito humano a capacidade de pensar e, por meio desse ato, entender a história como enredo para o qual é chamado a construir e intervir pela participação e não pela submissão.

É evidente que a correlação de forças possibilita a continuação da educação enquanto um processo de formação humana de indivíduos pensantes e críticos e não somente a manutenção dos interesses mercadológicos.

Com a educação mercantilizada e o Estado desobrigado do financiamento, entram em cena os organismos financeiros multilaterais, com a proposta de financiar a educação básica. Dentre eles, o Fundo Monetário Internacional (FMI) e o Banco Mundial (BM). No entanto, esse financiamento possui intencionalidades mais profundas:

\footnotetext{
[...] a tarefa do Banco assume um caráter cada vez mais político, pois o financiador passou a ser propositor do processo de desenvolvimento e, ao propô-lo, estabelece condicionalidades, dentre elas, a exigência de sua participação na definição de políticas de longo prazo para os setores financiados, neste caso as de educação (CANAN, 2016:68).
}

Diante desse cenário, fica evidente a intencionalidade desses organismos, dentre tantas, o alinhamento da educação aos interesses do grande capital, o que possibilita um 
certo controle ideológico da sociedade. Segundo Boito Jr (2016:26), a política econômica e social do Estado brasileiro, ao longo da década de 1990 e da primeira metade da década de 2000, conferiu ao capitalismo brasileiro certas características minimamente estáveis, que permitem que falemos em um novo modelo de desenvolvimento capitalista.

Esse novo modelo é denominado de neodesenvolvimentismo, que, segundo Boito Jr (2016), atende prioritariamente aos interesses da burguesia interna, enquanto o neoliberalismo atende aos interesses do capital internacional e de fração da burguesia brasileira a ele integrado. As contradições desse modelo acirraram a disputa pelo poder entre essas duas burguesias, justamente porque elas defendem doutrinas econômicas rivais. Esse embate se deu em duas frentes: de um lado o campo neoliberal ortodoxo que pretende iniciar novas reformas de cunho neoliberal no País e, do outro, o campo neodesenvolvimentista (BOITO Jr, 2016).

O resultado dessa disputa foi materializado no impeachment, também conhecido como Golpe, da presidente Dilma Rousseff (Partido dos Trabalhadores) em 2016, e na eleição do atual presidente, o que demonstra a predominância do campo neoliberal ortodoxo (SAAD-FILHO e BOITO JR, 2016). Na educação, essa predominância foi evidenciada na reforma do ensino médio e pelos recentes ataques à educação pública, principalmente às universidades, preconizados pelo Movimento Escola Sem Partido, que se corporificou em Projeto de Lei, tanto em âmbito nacional, materializado pelo PL 867, em trâmite tanto no Congresso como no Senado, como também nos estados, a exemplo do Amazonas com o PLO 102/ 2016, proposto pelo então deputado Platiny Soares (Partido Verde), cujo status de movimento preocupado com a doutrinação e os valores morais disseminados nas instituições públicas de ensino esconde a real intenção de seus arquitetos (SAAD-FILHO e BOITO JR, 2016; BOITO JR, 2017; FRIGOTTO, 2017).

\section{Princípio de neutralidade e ideal de doutrinação}

Hoje, a concepção educacional é predominantemente econômica, marcada pela ideologia neoliberal, cujas nuances podem ser percebidas no controle do financiamento por organismos financeiros internacionais, tais como Banco Mundial e Fundo Monetário Internacional, e consequentemente das políticas educacionais, como bem evidencia Peroni (2000) em sua obra intitulada Política educacional e papel do Estado no Brasil dos anos 90.

O programa Escola Sem Partido tem sido concebido, ao longo da história, por segmentos da classe dominante, revelando seus anseios e vontades para a educação, se aproximando dos interesses de manutenção do poder e de dominação. Esse Programa insere-se no contexto de reformas neoliberais defendidas pela burguesia alinhada ao campo neoliberal ortodoxo já relatado. O ideal neoliberal tem o encolhimento do Estado para com as questões sociais, como a educação, uma das principais características. 
Frigotto (2017) adverte que as teses do EsP não podem ser entendidas nelas mesmas, pois fazem parte de um movimento maior, cujas nuances podem ser percebidas a partir do contexto capitalista. Esse movimento se situa em uma conjuntura de desmonte dos direitos sociais, pois, para Krein (2018:87), os desmontes dos direitos sociais estão voltados para os

\begin{abstract}
[...] elementos centrais da relação de emprego e das instituições rEsPonsáveis pela normatização e efetivação das relações de trabalho. A sistematização das principais mudanças será realizada dialogando com aspectos destacados anteriormente em relação à agenda comum da observada internacionalmente. Por um lado, destacam-se os conteúdos em relação aos direitos: (1) formas de contratação e facilidades para dEsPedir; (2) jornada de trabalho; (3) remuneração da jornada; (4) condições de trabalho, EsPecialmente as que afetam a saúde e segurança no trabalho. Por outro, as questões que alteraram o papel e enfraquecem as instituições públicas: (1) alterações na regulamentação da representação dos interesses coletivos dos trabalhadores e da negociação coletiva; (2) limitações de acesso à Justiça do Trabalho; (3) engessamento de sistema de fiscalização de fraude.
\end{abstract}

No entanto, essas questões são preconizadas por uma crise do capital “[...] não mais cíclica, mas contínua, universal e global cada vez mais profunda" (FRIGOTTO, 2017:30), que vê na liquidação do Estado para com as questões sociais a solução para assegurar a manutenção dos lucros dos grandes grupos econômicos mundiais.

Além disso, Cara (2016) acrescenta que o Escola Sem Partido é inspirado em iniciativas internacionais e declara ter três objetivos: a "descontaminação e 'desmonopolização' política e ideológica das escolas"; o "rEsPeito à integridade intelectual e moral dos estudantes"; e o "rEsPeito ao direito dos pais de dar aos seus filhos uma educação moral que esteja de acordo com suas próprias convicções" (CARA, 2016:45).

O PL 102/2016 materializa esses objetivos, quando estabelece os seus princípios, que são:

Art. 1. Fica criado, no âmbito do sistema estadual de ensino, o Programa Escola Sem Partido, atendidos os seguintes princípios:

I - neutralidade política, ideológica e religiosa do Estado; II - pluralismo de ideias no ambiente acadêmico; III - liberdade de consciência e de crença; IV - liberdade de ensinar e de aprender; $\mathrm{V}$ - reconhecimento da vulnerabilidade do educando como parte mais fraca na relação de aprendizado; VI - educação e informação do estudante quanto aos direitos compreendidos em sua liberdade de consciência e de crença; VII - direito dos pais a que seus filhos não recebam a educação moral divergente de suas próprias convicções. (AMAZONAS, 2016, art. 1).

Quando comparados aos princípios estabelecidos na Constituição da República Federativa do Brasil de 1988 e na LDBEN (nº. 9.394/1996), percebemos que não são legítimos. Na verdade, vão de encontro aos princípios apresentados no artigo 206 da Constituição e artigo $3^{\text {o }}$ da LDBEN, os quais garantem: "II - liberdade de aprender, ensinar, pesquisar e divulgar o pensamento, a arte e o saber; III - pluralismo de ideias e de concepções pedagógicas. 
O princípio de neutralidade e o ideal de doutrinação no Artigo $2^{2}$ do PL ganharam destaque na mídia e serviram de argumento que fomentou o ataque às escolas, às universidades públicas e aos profissionais da educação, para desqualificar e desmoralizar a educação pública, como argumento que fundamentaria a defesa de sua privatização. Com relação ao ideal de doutrinação, ele permite o entendimento de que, na escola, os profissionais se aproveitam de sua condição para doutrinar os alunos e fazê-los apoiadores de um certo grupo político e religioso em detrimento dos outros, ignorando totalmente toda a concepção da educação, a própria legislação e o currículo. É como se os professores fizessem tudo conforme a sua vontade, como se não houvesse diretrizes que orientam a prática.

Sobre isso, Lima e Peroni (2018:125) apontam incoerência e inabilidade, alegando que, ainda que a doutrinação seja o foco do movimento, sua definição não é evidentemente explicitada em nenhum momento, apesar de que ela pode ser compreendida nas minúcias do conteúdo dos materiais elaborados pelo EsP. Essa proposta de neutralidade e de combate à doutrinação esconde sob uma cortina de fumaça as reais intenções dos seus propositores, que consistem na "[...] privatização do pensamento e a tese de que é apenas válida a interpretação dada pela ciência da classe detentora do capital" (FRIGOTTO, 2017:29). Essas propostas representam, na verdade, a reação da elite conservadora.

Além do mais, esse programa se fundamenta em bases argumentativas próprias do senso comum, pois não existem estudos científicos que comprovem as falácias dos idealizadores do programa, os quais se embasam, segundo Polizel (2019:4), em que

[...] as escolas brasileiras estariam, então, supostamente contaminadas e precisariam passar por um processo de 'descontaminação'. Essa perspectiva conclamada da 'desideologização' e 'descontaminação' não é nova e também não se dá apenas no território nacional brasileiro, pois ela se articula com movimentos autointitulados. No indocrination e com Think Tanks. Devido a tais alianças, o movimento EsP centra-se inicialmente em combates às epistemologias neomarxistas, evolucionistas e emancipadoras.

A referida contaminação estaria sendo feita pelos professores e a descontaminação se daria pelo estabelecimento de diretrizes que regulamentam, ou melhor, engessam a prática do professor. Nas propostas do PL 102/ 2016, essas diretrizes estão na instituição do Artigo $3^{\circ}$ :

Art. $3^{\circ}$. No exercício de suas funções, o professor:

I - não se aproveitará da audiência cativa dos alunos, para promover os seus próprios interesses, opiniões, concepç̃oes ou preferências ideológicas, religiosas, morais, políticas e partidárias; II - não favorecerá, não prejudicará e não constrangerá os alunos em razão de suas convicções políticas, ideológicas, morais ou religiosas, ou da falta delas; III - não fará propaganda político-partidária em sala de aula nem incitará seus alunos a participar de manifestações, atos públicos e passeatas; IV - ao tratar de questões políticas, socioculturais e econômicas, apresentará aos alunos, de forma justa, as principais versões, teorias, opiniões e perspectivas concorrentes a rEsPeito; V - rEsPeitará o direito dos pais a que seus filhos recebam a educação 
moral que esteja de acordo com suas próprias convicções; VI - não permitirá que os direitos assegurados nos itens anteriores sejam violados pela ação de estudantes ou terceiros, dentro da sala de aula (AMAZONAS, 2016, art. 3).

Sobre isso, Penna (2017:40) adverte que se trata de uma tentativa explícita de desqualificação do professor a partir da exclusão de suas atribuições, asseguradas pela Lei de Diretrizes e Bases da Educação Nacional (LDBEN 9.394/1996). Excluíram o pluralismo de concepções pedagógicas, excluíram a liberdade de ensinar, e vão mais longe quando propõem a exclusão da liberdade de expressão.

As autoras Lima e Peroni (2018:133) também fazem duras colocações, apontando que:

O objetivo final do movimento é romper com a possibilidade de construção de uma educação vinculada às questões e valores sociais, políticos e culturais existentes na diversidade, e que possibilitam o exercício de uma prática democrática na escola a partir de mecanismos de intervenção e participação coletiva estabelecidos através do princípio da gestão democrática, substituindo-a por uma educação sem EsPaço de participação, que promova a preservação acrítica do sistema capitalista e, consequentemente, das suas desigualdades.

E Algebaile (2017:71) ainda destaca que o programa EsP visa o “[...] controle prévio da atividade escolar, da atividade docente e da discussão educacional, a partir da disseminação da ameaça de exposição pública e de criminalização. Daí a propriedade da alcunha, atribuída a[o] PL por inúmeras vertentes críticas: Lei da Mordaça".

O que podemos salientar é que o programa proposto no PL 102/2016 não preconiza o combate às doutrinações partidárias ou ideológicas, e sim o cerceamento das práticas docentes, impedindo que o professor realize sua função de conduzir os alunos ao pensamento crítico e reflexivo.

Destacamos que em um momento em que grande parte do Parlamento brasileiro, assim como legisladores estaduais e municipais, busca menosprezar os debates acerca das injustiças sociais - a respeito da homofobia, misoginia, machismo, racismo etc. -, é basilar que as instituições escolares sejam, cada vez mais, progressistas e críticas, de modo a fazer com que o corpo docente e discente discuta os aspectos de tais injustiças.

Valem as palavras de Nicolazzi (2016:85) quando o autor expõe que

Nem refém da moralidade privada, nem subjugada pela lógica partidária: a escola é o lugar privilegiado para a educação pública, mas uma educação que depende das liberdades de ensino, de aprendizagem, de pesquisa e de divulgação do pensamento, como definido pela constituição.

Portanto, qualquer projeto ou programa que busca aniquilar o pensamento crítico da escola pública é uma atividade partidária, retrógrada, perigosa, além de um desserviço para toda a sociedade. E a partir disso, fica a pergunta de Nicolazzi (2016): qual o partido do Escola Sem Partido? 


\section{Considerações finais}

O Programa Escola Sem Partido proposto no Projeto de Lei Ordinária 102/2016 no estado do Amazonas é a materialização da própria contradição, porque defende uma neutralidade que ele mesmo não expressa. Manhas (2016) ressalta que nada mais ideológico que o Escola Sem Partido, que concebe uma educação que vai ao encontro da própria história da concepção de educação no Brasil, onde ela sempre esteve alinhada predominantemente a uma visão de mundo e de sociedade da classe dominante (ideologia).

Como bem afirmou Freitag (2005), a educação sempre expressa uma doutrina pedagógica, que se baseará implícita ou explicitamente em uma filosofia de vida, concepção de homem e sociedade. Atualmente, essa filosofia de vida, concepção de homem e de sociedade é baseada no ideal neoliberal, e a educação a expressa também; por isso, não tem como conceber uma educação neutra, pois ela se relaciona diretamente com a sociedade, que, no caso, é a capitalista e com membros dessa sociedade, no caso, as classes socias. A própria concepção desse PLO expressa uma consciência social, uma ideologia acerca da educação escolar. Ela traz em seu escopo um entendimento do que seja escola e prática docente, bem evidenciado no Art. $2^{\circ}$, que fala em doutrinação política e ideológica e no Art. 3ㅜㅜ que discorre sobre a prática do professor, o qual não usará da audiência cativa para cooptar os alunos.

Outro propósito desse programa é a manutenção do poder da burguesia, o qual só é possível pelo controle ideológico das massas. E, ao encontro disso, Freitag (2005) relata que uma forma de se conseguir é pela inviabilização da circulação de uma contraideologia, que normalmente é disseminada nos espaços educacionais; por isso a necessidade que Algebaile (2017) fala de controlar a atividade escolar, a prática docente e as discussões educacionais. Isso justifica o ataque à educação e seus profissionais, através da implementação da pedagogia do medo e da violência (FRIGOTTO, 2017), principalmente nas escolas e universidades públicas, lugar onde estão as massas.

Na educação pública, o programa se configura na tentativa de desmonte, por meio da desmoralização do espaço e da desqualificação e demonização dos seus profissionais; de quebra, assegura que grupos historicamente marginalizados não tenham a possibilidade de ascender socialmente e ocupar lugares e cargos no aparelho estatal que, historicamente, são reservados a essa elite.

Os ataques à educação possibilitados pelo programa vislumbrado a partir do Projeto de Lei fazem parte de um movimento maior, que ocorre em escala mundial e que pode ser entendido a partir do contexto capitalista e suas crises e que, no Brasil, tem explicação na predominância do neoliberalismo ortodoxo em detrimento do neodesenvolvimentismo (BOITO, 2016).

No entanto, a partir dessa iminente desconstrução da educação pública, notamos a reação da classe trabalhadora, manifestada a partir dos profissionais da educação e dos 
próprios estudantes, principalmente do ensino superior. Eles compreenderam que a articulação com a sociedade civil é fundamental para a manutenção desses espaços. Como consequência disso, surgiram projetos como "ciência na rua", em que estudantes levam suas pesquisas para a rua e os apresentam, na tentativa de derrubar os argumentos do movimento EsP tais como "doutrinação", "universidade pública só tem aluno drogado", "balbúrdia", mostrando que a universidade pública é um espaço importante, assim como a escola, que alunos fazem ciência e que professores compartilham o saber.

Resumindo o Programa Escola Sem Partido proposto no PLO 201/2016, em poucas palavras seria a "esfinge que ameaça a educação e a sociedade brasileira" (FRIGOTTO, 2017). No entanto, podemos vislumbrar, a partir da contrarreação da classe trabalhadora, num processo de correlação de forças percebidas nos manifestos do 15 de maio convocado pelos professores, no de 30 de maio convocado por estudantes e dia 14 de junho também pelos professores, e que reuniu grupos de diversos setores, como partidos e sindicatos, além de civis, a possibilidade de inviabilizar esses desmontes e de conscientizar a sociedade sobre esses argumentos e mostrar a real intenção de quem os propaga. Ao mesmo tempo que buscamos assegurar esses direitos, frutos de lutas das outras gerações.

Recebido em 01/08/2020. Aprovado em 13/08/2020.

\section{Notas}

1 O desenvolvimento do artigo contou com o apoio da Universidade Federal do Amazonas e da Coordenação de Aperfeiçoamento de Pessoal de Nível Superior.

2 Nos primeiros 30 anos do século XX o mundo passou por várias catástrofes. A título de exemplificação, ganham destaque: Primeira Guerra Mundial (1914-1918) - centrada na Europa, o conflito envolveu duas grandes potências e resultou na morte de mais de nove milhões de soldados; Crise de 1929 - conhecida como Grande Depressão Econômica, foi o maior período de recessão econômica do sistema capitalista do século XX, causando enormes taxas de desemprego e diminuição do PIB de inúmeros países; ascensão de ditaduras - $\mathrm{O}$ fascismo apareceu pela primeira vez no ano de 1922, com Mussolini na Itália (HOBSBAWM, 1995).

\section{Referências}

ALGEBAILE, Eveline. Escola sem Partido: o que é, como age, para que serve. In: FRIGOTTO, Gaudêncio (Org). Escola "Sem" Partido: esfinge que ameaça a educação e a sociedade brasileira. Rio de Janeiro: UERJ, LPP, 2017. pag. 63-74.

AMAZONAS. Projeto de Lei Ordinária n⿳0 102/2016. Disponível em: https://sapl.al.am.leg.br/ materia/95445. Acesso em: 20 de ago. 2019. 
BEHRING, Elaine Rossetti. Política social: fundamentos e história/ Elaine Rossetti Behring, Ivanete Boschetti. - 9. Ed. - São Paulo: Cortez, 2011. - (Biblioteca básica de serviço social: v. 2).

BOITO JR, Armando. A crise Política do Neodesenvolvimentismo e a instabilidade da democracia. Rev. Crítica Marxista, São Paulo, v. 1, n. 42, p. 155-162, mai. 2016.

BRASIL. Constituição da República Federativa do Brasil [Constituição (1988)]. [recurso eletrônico]. Brasília: Supremo Tribunal Federal, Secretaria de Documentação, 2018.

BRASIL. Lei de Diretrizes e Bases da Educação Nacional - Lei no . 9.394/1996. Brasília: Presidência da República, 1996.

BRASIL. Projeto de Lei no 867/2015, que institui Programa Escola sem Partido. Disponível em: https:// www.camara.leg.br/proposicoesWeb/fichadetramitacao?idProposicao=1050668. Acesso em: 17 de jul. 2019.

CANAN, Silvia Regina. Influências dos organismos internacionais nas políticas educacionais: só há intervenção quando há consentimento? Campinas: Mercado de Letras, 2016.

CANDAU, Vera Maria. Interculturalidade e Educação Escolar. In: CANDAU, Vera Maria (Org.). Reinventar a escola. Petrópolis: Vozes, 2000. p. 47-60.

CARA, Daniel. O programa "escola sem partido" quer uma escola sem educação. In: AÇÃO EDUCATIVA ASSESSORIA, PESQUISA E INFORMAÇÃO (Org.). A ideologia do movimento Escola Sem Partido: 20 autores desmontam o discurso. São Paulo: Ação Educativa, 2016. p. 43-49.

FARIA FILHO, L. M. Instrução elementar no século XIX. In: LOPES, Eliane Maria Teixeira; FARIA FILHO, Luciano Mendes; VEIGAS, Cynthia Greive (Orgs.). 500 anos de educação no Brasil. 5. ed. Belo Horizonte: Autêntica, 2015. p. 35-53.

FERREIRA JR, Amarilio; BITTAR, Marisa. A gênese das instituições escolares no Brasil: os jesuítas e as casas de bê-a-bá no século XVI. Acervo, Rio de Janeiro, v. 18, n. 1-2, p. 35-54, jan./dez., 2005.

FREITAG, Barbara. Escola, Estado e sociedade. $7^{a}$ ed. rev. São Paulo: Centauro, 2005.

FRIGOTTO, Gaudêncio. A gênese das teses do Escola sem Partido: esfinge e ovo da serpente que ameaçam a sociedade e a educação. In: FRIGOTTO, Gaudêncio (Org). Escola "Sem" Partido: esfinge que ameaça a educação e a sociedade brasileira. Rio de Janeiro: UERJ, LPP, 2017. p. 17-34.

FRIGOTTO, Gaudêncio. A produtividade da escola improdutiva: Um (re)exame das relações entre educação e estrutura econômico-social capitalista. São Paulo: Cortez, 2010.

HOBSBAWN, Eric J. Era dos Extremos: o breve século XX - 1914-1991. Tradução: Marcos Santarrita. São Paulo: Companhia das Letras, 1995.

KREIN, José Dari. O desmonte dos direitos, as novas configurações do trabalho e o esvaziamento da ação coletiva. Disponível em: http://www.scielo.br/pdf/ts/v30n1/1809-4554-ts-30-01-0077.pdf. 2018, pp. 77-104. Acesso em: 08 de ago. 2019.

LIMA, Paula Valim de; PERONI, Vera Maria Vidal. Escola sem partido e as implicações para a democratização da educação. Revista Pedagógica, Chapecó, v. 20, n. 44, p. 121-136, mai./ago. 2018.

MANHAS, Cleomar. Nada mais ideológico que "escola sem partido". In: AÇÃO EDUCATIVA ASSESSORIA, PESQUISA E INFORMAÇÃO (Org.). A ideologia do movimento Escola Partido: 20 autores desmontam o discurso. São Paulo: Ação Educativa, 2016. p. 15-22. 
NICOLAZZI, Fernando. Qual o partido da escola sem partido? Revista do Lhiste, Porto Alegre, v. 03, n. 05, p. 82-85, jul./dez., 2016.

PASINATO, Darciel. Educação no período populista brasileiro (1945-1964). Semina, Passo Fundo, v. 12, n. 1, p. 1-13, out., 2013.

PENNA, F. Ódio aos Professores. In: AÇÃO EDUCATIVA ASSESSORIA, PESQUISA E INFORMAÇÃO (Org.). A ideologia do movimento Escola sem Partido: 20 autores desmontam o discurso. São Paulo: Ação Educativa, 2017. p. 93-100.

PERONI, Vera; CAETANO, Maria Raquel. Redefinições no papel do estado: terceira via, novo desenvolvimentismo e as parcerias público-privadas na Educação. Anais do IX Seminário de Pesquisa em Educação da Região Sul, Caxias do Sul- RS, 2012.

PERONI, Vera. O estado brasileiro e a política educacional dos anos 90. Anais da $23^{a}$ Reunião Anual da ANPEd, Caxambu, 2000.

PERONI, Vera; CAETANO, Maria Raquel; LIMA, Paula de. Reformas educacionais de hoje: as implicações para a democracia. Revista Retratos da Escola, Brasília, v. 11, n. 21, p. 415-432, jul./dez. 2017.

POLIZEL, Alexandre. Percepções do movimento escola sem partido: currículos pastorais e o professor como catequista. Revista Amazônida, Manaus, v. 4, n. 1, p. 01-16, fev. 2019.

SAAD-FILHO, A.; BOITO, A. Brazil: The Failure of the PT and the Rise of the 'New Right', Socialist Register, Londres, v. 52, n. 1, p. 213-230, 2016.

SBARDELOTTO, Denise Kloeckner. Educação no regime civil-militar (1964-1985) no Brasil e a Teoria do Capital Humano. Anais do XI Jornada do HISTEDBR: a Pedagogia Histórico-Crítica, a educação brasileira e os desafios de sua institucionalização, v. 11. p. 1-18, Cascavel - PR, 2013.

SILVA, Edilaine Cristina da; LENARDÃO, Edmilson. Teoria do capital humano e a relação educação e capitalismo. s/d. Disponível em: http://www.uel.br/eventos/sepech/sumarios/temas/teoria_do_capital_ humano_e_a_relacao_educacao_e_capitalismo.pdf. Acesso em: 17 de jul. 2019.

TEIXEIRA, Anísio [1900-1971]. Ensino superior no Brasil: análise e interpretação de sua evolução até 1969/Anísio Teixeira. Rio de Janeiro: Editora da Fundação Getúlio Vargas, 1989.

VEIGA, Cynthia Greive. Escola pública para os negros e os pobres no Brasil: uma invenção imperial.

Revista Brasileira de Educação, Rio de Janeiro, v. 13, n. 39, p. 502-516, set/dez 2008. 